\title{
1 Predation impacts late but not early community assembly in model marine biofilms.
}

2

3 Sven P. Tobias-Hünefeldt ${ }^{1,2}$, Jess Wenley ${ }^{1,2}$, Federico Baltar $^{3, *}$ and Sergio E. Morales ${ }^{1, *}$

4

$5{ }^{1}$ Department of Microbiology and Immunology, University of Otago, PO Box 56, Dunedin

69054 , New Zealand

$7{ }^{2}$ Department of Marine Science, University of Otago, PO Box 56, Dunedin 9054, New

8 Zealand

$9{ }^{3}$ Department of Limnology and Oceanography, Division of Bio-Oceanography, University of

10 Vienna, Althanstrasse 14, A-1090 Vienna, Austria

$12 *$ Correspondance:

13 Dr. Sergio E. Morales, University of Otago, Department of Microbiology and Immunology,

14720 Cumberland Street, North Dunedin, Dunedin 9054, New Zealand

15 Email: sergio.morales@otago.ac.nz, Phone: + 6434793140

16

17 Running title: Selection switching during community succession

18 Keywords: Top-down selection, Bottom-up selection, Biofilm, Environmental filtering,

19 Community assembly 


\section{Abstract}

22 Bottom-up selection plays an important role in microbial community assembly but is unable

23 to account for all observed variance. Other processes like top-down selection (e.g. predation)

24 may be partially responsible for the unexplained variance. However, top-down processes

25 often remain unexplored, especially in interaction with bottom-up selective pressures. We

26 utilised an in situ marine biofilm model system to test the effects of bottom-up (i.e. substrate

27 properties) and top-down (i.e. predator exclusion via $100 \mu \mathrm{m}$ mesh) selective pressures on

28 community assembly over time (56 days). Community compositions were monitored using

$2916 \mathrm{~S}$ and $18 \mathrm{~S}$ rRNA amplicon sequencing. Wooden substrates promoted heterotrophic growth,

30 while the inert substrates' (i.e., plastic, glass, tile) lack of degradable material selected for

31 autotrophs. Early wood communities contained 9-50\% more mixotrophs and heterotrophs

32 (e.g. Proteobacteria and Euglenozoa) compared to inert substrates. Inert substrates instead

33 showed twice the autotrophic (e.g. Cyanobacteria and Ochrophyta) abundance. Late

34 communities differed mainly due to exclusion status, as large predators preferably pruned

35 heterotrophs. This resulted in the autotrophic domination of native communities, while high

36 heterotrophic abundance characterised exclusive conditions. Top-down control through

37 exclusion increased explainable variance by $18-53 \%$, depending on community age, leading

38 to increased understanding of the underlying ecological framework that guides microbial

39 community assembly. 


\section{Introduction}

43 Sequencing technology advances have increased insight into microbiome compositions

44 across all ecosystems, but mechanistic understanding of community succession remains poor.

45 Historic pure culture approaches, which remove biotic interactions, have led to a focus on

46 resource limitations as a mechanism to explain differences in growth and community

47 composition $^{1,2}$. However, biotic interactions have the potential to impact microbiome

48 assembly and composition ${ }^{3}$. Microbiome studies generally report $20-67 \%{ }^{4-6}$ unexplained

49 composition variance when utilising solely resource limitations as a selective pressure.

50 Unexplained variance represents a fundamental knowledge gap within the microbial ecology

51 field and suggests that other processes must be contributing to microbiome changes.

52 Previous studies have found that communities can be shaped by two possible

53 overarching processes: stochastic and deterministic. A stochastic process increases a

54 community's inherent randomness, producing variable microbiomes under identical

55 conditions $^{7}$. Early communities are commonly stochastic ${ }^{8}$, the inherent randomness of

56 dispersal and ecological drift driving composition ${ }^{9,10}$. In contrast, deterministic processes,

57 focused upon in the present study, shape communities by selecting for or against specific

58 organisms $^{11-13}$. These complementary processes shape structure by representing extremes

59 along the same continuum, and a process such as dispersal may be equally stochastic and

60 deterministic in a context and habitat-dependent manner ${ }^{9}$. Dispersal rates are stochastic if

61 they rely on population size, but species traits and their activity level mean that dispersal can

62 also be deterministic 9 .

63 Both abiotic and biotic deterministic processes can influence community assembly.

64 Abiotic factors are chemical or physical environmental components (such as nutrients, $\mathrm{pH}$,

65 temperature, pressure) that affect community composition and function ${ }^{14-16}$. Meanwhile

66 biotic factors are defined as selective pressures related to, or resulting from, living organisms 
67 that may affect community composition. Biotic factors can concern the biotic interactions between organisms, and these interactions can result in the promotion or inhibition of 69 organism abundance. The cooperation between microbes ${ }^{17,18}$, and microbes and higher 70 trophic levels (i.e. larger predators) increases both participants' abundance. One such 71 example is a Copepods ability to affect environmental community compositions by farming 72 their own microbiome ${ }^{19}$. Meanwhile predation promotes the growth of one organism at the 73 expense of another ${ }^{20,21}$. Both abiotic ${ }^{22}$ and biotic ${ }^{23}$ factors are dynamic throughout space and 74 time. These shifting environmental conditions and biotic interactions change the community 75 over time due to continuous selective pressures ${ }^{22,24,25}$.

76 Selective pressures enact compositional changes through autotrophs (i.e. primary 77 producers) in a bottom-up dependent manner ${ }^{26}$, or through predators in a top-down dependent 78 manner $^{27}$. Previous studies on environmental microbiology have typically focused on bottom79 up controls ${ }^{4,28}$. Field studies concerning top-down controls are rarer, and bottom-up and top80 down selective pressure interaction effects on microbial communities remain largely 81 unexplored ${ }^{29-34}$. Bottom-up microbiome studies commonly report unexplained variance, 82 which could be partially driven by top-down controls ${ }^{35,36}$. Identifying the contribution of top83 down controls to total variance is crucial to better understand community assembly 84 mechanisms. Therefore, our study focuses on comparing the effects of bottom-up (i.e. 85 different substrate surface) and top-down (i.e. predator presence and exclusion via a mesh 86 enclosure) on compositional variance within marine biofilms.

87 We aim to quantify the influence of top-down and bottom-up controls on community assembly in a model marine biofilm system. We hypothesise that bottom-up controls drive

89 early assembly, while established communities are controlled equally by both bottom-up and 90 top-down mechanisms. To test these hypotheses, we created a model biofilm system using 91 four different substrates (i.e. plastic, glass, tile, wood) to represent a degradability and surface 
92 property gradient and thus bottom-up selection. Biofilms were reared in situ under native

93 (non-enclosed) or enclosed (exclusion with $100 \mu \mathrm{m}$ mesh) conditions to model top-down

94 influence by limiting predator access. Prokaryotic and eukaryotic community successions and

95 composition were monitored via $16 \mathrm{~S}$ and $18 \mathrm{~S}$ rRNA amplicon sequencing over a 56-day

96 period. We used here an in situ marine biofilm as a model system to study the integration of

97 both bottom-up and top-down selective pressures on microbial communities assembly. Yet,

98 the knowledge derived from this experiment would be applicable across all ecosystems, as

99 we assess the underlying framework rather than habitat specific processes. 
102 Individual $75 \times 25 \mathrm{~mm}$ substrate slides (glass, tile [i.e. glazed ceramic], plastic [i.e. acryl],

103 and wood [i.e. untreated pine]) were inserted into PVC pipe sections using polyethylene foam

104 and ethyl cyanoacrylate. The substrates and their holders were then either sewn into $25.4 \mathrm{x}$

$10530.5 \mathrm{~cm} 100 \mu \mathrm{m}$ mesh enclosures to protect from predation vie exclusion or left exposed to

106 the native environment (Supplementary Figure 1).

107 Substrates were submerged in the Otago Harbour, New Zealand (45.826678 S, 170.641684

108 E). Samples were suspended from a rope using cable ties $80 \mathrm{~cm}$ from the seabed, remaining 109 exposed during low-tide but submerged during high-tide. All samples were located in a small 110 geographic area $\left(<30 \mathrm{~m}^{2}\right), 50$ metres from shore.

111 Starting in May 2019 triplicate biofilm sampling was completed on days 7, 14, 19, 28, 42, 112 and 56. However, due to sample loss as a result of the in situ environment, a total of 153 113 biofilm samples were obtained (Supplementary Table 1). Biofilm was scraped off the entire 114 substrate using a sterile scalpel. Tiles were scraped only on the glazed side. Samples were 115 suspended in $100 \mu \mathrm{L}$ sterile Milli-Q water and stored at $-80^{\circ} \mathrm{C}$ until further processing.

116 Duplicate 1L water samples were collected 2 metres from both ends of the substrate 117 suspension structure on days $0,7,14,19,28,42$, and 56. Samples were filtered through a $1180.22 \mu \mathrm{m}($ diameter $=47 \mathrm{~mm})$ polycarbonate filter prior to freezing and storage at $-80{ }^{\circ} \mathrm{C}$ until 119 further processing. 
120 All data analysis was carried out using $\mathrm{R}$ version 3.6.1 within RStudio ${ }^{71}$, and visualised

121 using the ggplot2 package (version 3.2.1) ${ }^{72}$ unless otherwise stated. All code and associated

122 files are available at https://github.com/SvenTobias-Hunefeldt/Biofilm_2020/.

\section{DNA Extraction and Sequencing}

124 DNA was extracted using the Qiagen DNeasy ${ }^{\circledR}$ PowerSoil ${ }^{\circledR}$ Kit (MoBio Laboratories,

125 Carlsbad, CA, USA) according to the manufacturer's protocol. DNA was then dehydrated

126 using rotary evaporation in an Eppendorf Concentrator 5301(Eppendorf, Germany) at $30^{\circ} \mathrm{C}$

127 for 1 hour. Community profiles were generated using barcoded 16S (targeting the V4 region:

$128515 \mathrm{~F} \quad\left[5^{\prime}\right.$-NNNNNNNNGTGTGCCAGCMGCCGCGGTAA- $\left.\quad 3^{\prime}\right] \quad$ and $806 \mathrm{R} \quad\left[5^{\prime}-\right.$

129 GGACTACHVGGGTWTCTAAT-3']) or 18S (1391f [5'- GTACACACCGCCCGTC-3'] and

130 EukBr [5'- TGATCCTTCTGCAGGTTCACC TAC-3']) rRNA gene primers as per the Earth

131 Microbiome Project protocol ${ }^{73}$. Barcoded samples were then loaded onto separate Illumina

132 MiSeq $2 \times 151$ bp runs (Illumina, Inc., CA, USA) to produce a total of 13,202,642 and

$13310,124,722$ reads for $16 \mathrm{~S}$ and $18 \mathrm{~S}$ runs, with an average of 63,171 and 48,444 per sample and

134 a standard deviation of 28,248 and 18,473. All sequence data from this study has been

135 deposited in NCBI under BioProject PRJNA630803.

$13616 \mathrm{~S}$ and $18 \mathrm{~S}$ rRNA sequencing reads were quality filtered and assigned to amplicon

137 sequencing variants (ASVs) using the dada2 R package (version 1.12.1) and associated

138 pipeline ${ }^{74}$. Taxonomies were assigned in accordance to the dada2 pipeline from the SILVA

139 rRNA reference database (version 132) using the Ribosomal Database Project (RDP) naïve

140 Bayesian classifier method ${ }^{75}$. All data was imported into $\mathrm{R}$ for further analysis with the

141 phyloseq R package (version 1.28.0) ${ }^{76}$. 
142 The optimum sequencing depth was identified with a custom function utilising functions

143 from the phyloseq, reshape2 (version 1.4 .3$)^{77}$, plyr (version 1.8 .4$)^{78}$, base (version 3.6.1) ${ }^{71}$,

144 stats (version 3.6.1) ${ }^{71}$, and data.table packages (version 1.12.1) ${ }^{79}$. Samples were rarefied 10

145 times at 11000 reads using rarefy_even_depth() from the phyloseq package. This depth

146 retains both the maximum number of samples and sequencing depth (Supplementary Figure

147 2). Independent rarefactions were combined and underwent sample count transformations

148 using transform_sample_counts() from the phyloseq package to account for multiple

149 rarefactions. To avoid fractional representation of counts all data was rounded to the nearest

150 possibility using the round() command from the stats package. All data analysis used rarefied

151 data unless otherwise stated.

\section{Community analysis}

153 Observed richness was quantified using estimate_richness() from the phyloseq package, and

154 significance analysed using stat_compare_means() from the ggpubr package (version 0.2.4)

$155{ }^{80}$. Phyloseq package generated NMDS plots assessed Beta-diversity, with ggplot2 and

156 ggpubr package adjustments. Clustering was assessed using ADONIS and ANOSIM

157 statistical tests, with the vegan package (version $2.5-6)^{81}$, pairwise PERMANOVA tests

158 identifying significant sample to sample differences. Spearman correlations were used to

159 assess relationships between biofilm age and NMDS1 of the whole community NMDS. Intra-

160 time dissimilarity was calculated with the vegan and phyloseq package, removing self-

161 comparison using the dplyr package (version 0.8 .3$)^{82}$. Significant differences between time-

162 points were identified with the stats package. The number of shared organisms was calculated

163 using Zeta.decline.mc() from the zetadiv package (version 1.1.1) ${ }^{83}$.

164 Comparisons of means between two groups, such as biofilm succession stages and predated

165 conditions, were done with Wilcoxon tests. In the case of more than two groups Kruskal- 
166 Wallis tests were used, e.g. differences between biofilm ages and substrates. Pairwise

167 Wilcoxon tests compared individual timepoints and substrates.

168 To test for taxonomic composition changes we determined what organisms significantly

169 changed over time using the EdgeR package (version 3.22.3) ${ }^{84}$ and an exact test using only

170 biofilm samples. The legend was ordered according to mean relative abundance with the

171 forcats package (version 0.4.0) ${ }^{85}$. All $\mathrm{p}$ values were FDR adjusted using Bonferroni. A

172 literature search was used to classify phyla as either autotrophs ${ }^{86-89}$, heterotrophs ${ }^{51,60,61,90-98}$,

173 mixotrophs ${ }^{90,91,99,100}$, or unknown if the literature was lacking. Unknown taxonomies were

174 excluded due to their low abundance (Supplementary Table 1), and unknown role in

175 predator-prey dynamics.

176 Rare taxa (phyla making up less than $1 \%$ of the total abundance) were identified using the

177 plyr package and standard error, standard deviation and the $95 \%$ confidence interval

178 calculated with the Rmisc and dplyr packages. 


\section{Biofilm maturation is divided into two stages}

182

183 Biofilms across all treatments could be separated into two distinct succession stages: early

184 and late. Silhouette analyses identified that prokaryotes were best divided into 2 groups,

185 predominantly based on community age, whereas eukaryotic groupings could not be reliably

186 identified. Ecotone analyses found only 2 (day 7 and 14 for prokaryotes) and 1 (day 7 for

187 eukaryotes) out of 6 time-points categorized as early stage (Supplementary Figure 3).

188 Richness and compositional patterns were in agreement with the rapid successions. Richness

189 increased with biofilm age (Kruskal-Wallis, chi $^{2}>19, \mathrm{p}<0.01$ ) with a late-stage 1.9-fold

190 increase compared to the early-stage (Figure 1 A-B) (Wilcoxon, chi $>407, \mathrm{p}<0.01$ ).

191 Pairwise analyses further confirmed differences between succession stages (Wilcoxon $\mathrm{p}<$

192 0.03), with non-significant intra-stage differences (Wilcoxon $\mathrm{p}>0.06$ ). Compositional

193 patterns also exhibited stage significant grouping, both when comparing group means

194 (ANOSIM, $\mathrm{R}=0.67, \mathrm{p}<0.01$ ) and when taking variability into account (ADONIS, $\mathrm{R}^{2}=$

195 0.13, $\mathrm{p}<0.01)$. Additionally, community dissimilarity displayed stabilisation from day 19

196 (prokaryotes) and 14 (eukaryotes) to 42 (Figure $1 \mathrm{C}$ ), with early-stage samples sharing less

197 ASVs (Amplicon Sequence Variants) across substrates (Figure 1 D).

199 Rapid successions lead to community convergence across substrates

201 Rapid community successions were observed with sequential clustering in response to

202 biofilm age (Table 1, Figure 2). Biofilm age also significantly correlated with NMDS1

203 (Figure 2) (Spearman, rho $>0.66, \mathrm{p}<0.01$ ), and both maturation and sequential clustering

204 coincided with community convergence across substrates. Variance between substrates and 
205 enclosure status decreased over time, especially when comparing specific time points 206 between early and late community stages, such as day 7 and 56 (Figure 1 C). However,

207 prokaryotic variance decreases were more pronounced than for eukaryotes $(28 \%$ and $9 \%$

208 across the experiment for prokaryotes and eukaryotes, respectively) (Figure 1 C). Both

209 prokaryotes and eukaryotes showed increased ASV sharing across substrates over time

210 (Figure 1 D). The number of shared ASVs across substrates increased from 1.8 (prokaryotes)

211 and $3.3 \%$ (eukaryotes) to 22 and $9.4 \%$ respectively of the total number of community ASVs

212 based on richness. Predator exclusion increased the rate of prokaryotic community

213 maturation (this difference could be quantified as a dissimilarity increase of $0.02 \%$ per day).

214 Over 56 days the difference in community succession velocities lead to a maximum

215 dissimilarity of $11.2 \%$, however, day 56 prokaryotic communities are a mean $61 \%$ dissimilar.

216 Community convergence was associated with a transition from bottom up to top down

217 control. Early clustering was strongest due to substrate choice (Table 1, Figure 2), with a

218 distinct wood composition (pairwise MANOVA, $\mathrm{p}<0.03$ ), and no observable early stage

219 distinctions between enclosure status (Supplementary Figure 4). Meanwhile late communities

220 clustered primarily due to enclosure differences (Table 1, Supplementary Figure 4) with

221 minimal substrate dependent grouping (Figure 2).

223 Native conditions displayed decreased alpha diversity, with some substrate effects

225 Predator exclusion exerted noticeably more pressure on late than early communities.

226 Exclusion increased late stage richness by 2-fold (Wilcoxon $\mathrm{p}$ value $<0.01$ ) (Figure 3, Figure

227 1 A-B) while early communities remained unaffected (Wilcoxon $\mathrm{p}>0.06$ ). Substrate-specific

228 differences were enclosure-dependent: 100-250 more organisms were detected within early

229 native prokaryotic and late exclusive eukaryotic wood communities compared to more inert 
230 substrates (Figure 3). On average 42 less prokaryotic ASVs were detected on wood compared

231 to inert substrates, while eukaryotes had a mean of 79 more ASVs on wood (Figure 3).

232 However, prokaryotic substrate richness differences were only significant when wood

233 contained an increased number of ASVs compared to inert substrates, such as under native

234 early conditions. Overall, richness was primarily driven by enclosure condition, with some

235 substrate dependent differences.

Shifts in dominant taxa reflect changes in selective pressures

Phylum level changes were observed in response to switch in bottom-up to top-down control

mechanisms (Figure 4). Early communities differed primarily by substrates; wood displayed

9-50\% more Proteobacteria and Euglenozoa and half the number of autotrophs compared to inert substrates (Supplementary Table 2). The absence of an enclosure caused the main

difference in late composition which displayed no consistent substrate effect. Enclosed

biofilms were dominated by mixotrophs and heterotrophs while native conditions contained

high autotroph values. Late enclosed community autotroph relative abundance was half of the non-enclosed conditions. Ochrophyta abundance, predominantly diatoms, decreased from $>$

$24736 \%$ to $\sim 15 \%$ across all substrates. Meanwhile, Cyanobacteria abundance increased in glass, 248 tile, and acyl plastic from $<30 \%$ to $>53 \%$ from days 7 to 14 , and then decreased to $\sim 17 \%$,

249 whereas wood Cyanobacteria abundance rose by $10 \%$. However, with autotroph decreases 250 came mixotroph and heterotroph increases. Over 56 days Proteobacteria abundance increased

251 by a mean $16.7 \%$ while Bacteroidetes, Ciliophora, and Arthropoda abundance rose by $11 \%$, $25221 \%$, and 49\% (Supplementary Table 2). Within non-enclosed biofilms Bacteroidetes, 253 Ciliophora, and Arthropoda stayed $<25 \%$ abundance, while Cyanobacteria increased by $21 \%$ 254 within wood and remained $>45 \%$ within all other substrates. Early autotroph-heterotroph 
255 balances are therefore due to bottom-up substrate differences. Followed by a primary

256 selective pressure switch, that decreased early community differences, through decreases of

257 heterotroph previously abundant on wood until late autotroph-heterotroph distributions were

258 enclosure dependent.

259 
261 Our results show that the analysis of bottom-up selective pressures (i.e. substrate differences)

262 are sufficient to determine the majority of community variance when assessing drivers of

263 early unstable communities, but the study of top-down selective pressures (i.e. predation via a

264 mesh enclosure) is essential when assessing assembly mechanisms of established

265 environments as it determines the majority of community variance. This supports the

266 hypothesis that early communities are primarily driven by bottom-up controls but did not

267 support our prediction for late communities. Late taxonomic and diversity patterns were

268 instead predominantly determined by top-down control. From our results, we created a

269 community assembly model (Figure 5) describing the effect of sequential bottom-up and top-

270 down control over time. Initial community settlement is a stochastic process that results in

271 large variation. Subsequent growth is then determined primarily by nutritional availability

272 and results in distinct compositions based on dominant factors like availability and type of

273 nutrients (i.e. degradable vs non-degradable substrates). Early bottom-up control weakens

274 over time until late compositions are modified by top-down selective pressures. This work

275 addresses some of the controversy in the field of ecology, by quantifying the relative effects

276 of bottom-up and top-down selective pressures over time. This approach also assesses the

277 effects of top-down pressures on community composition and assembly in more complex

278 environments, which represents a gap in the literature ${ }^{37,38}$. Below we discuss the transition

279 from a stochastically settled to a top-down controlled community via convergent selection, as

280 well as the effects of substrate properties and predation on compositional patterns.

\section{Stochastic settlement transitions to convergent community assembly}

282 Settlement is primarily a stochastic process, while subsequent deterministic processes result 283 in convergence. Previous studies have found that dispersal and selection influence 
284 composition ${ }^{7,8}$. The limited geographical range of our study controls for unequal dispersal,

285 so encounter rates dictated early composition. Large early community confidence intervals

286 and intra-age dissimilarities thereby reflect the inherent stochasticity of early-stage selection.

287 Previous studies have found that early assembly is dictated predominantly by stochastic

288 mechanisms ${ }^{39}$. However, deterministic processes may still play a role in settlement. Early

289 settlers must adhere to the substrate surface for colonisation, and a mesh enclosure excluded

290 organisms over $100 \mu \mathrm{m}$. Yet no enclosure-specific visual clustering was identified within

291 early biofilms. A size exclusion method was chosen as predators tend to be larger than their

292 prey ${ }^{40}$. Previous work has also shown that larger organisms (e.g. macro-algae and macro-

293 eukaryotes) are not primary settlers, and instead prefer established and complex communities

$294{ }^{41}$. Therefore, while surface attachment was a critical process, the enclosure size exclusion

295 had no effect on settlement.

296 Following settlement, communities can develop either divergently ${ }^{42-44}$ or convergently ${ }^{5,43,45}$,

297 with evidence for both rife within the literature. Stochastic fluctuations throughout time and

298 the creation of new genetic variation, drift and diversification, are characteristic of time-

299 dependent ecological studies ${ }^{7}$ and lead to divergence with increased dissimilarity over time.

300 Our study however displayed convergence via an increased number of shared organisms over

301 time and decreased dissimilarity. The rise of convergence is most likely an artefact of

302 preconditioning ${ }^{46}$ due to the geographically-limited environment and therefore decreased

303 organism variability, and the surface adhesion requirement. Another point in favour of

304 convergence is derived from deterministic succession ${ }^{12}$. Community age correlated with the

305 primary axis of dissimilarity (NMDS1) and clustered in response to biofilm age. These

306 characteristics imply succession due to sequential compositional changes, with the same

307 organisms filling identical ecological niches. Based on the evidence we conclude that

308 compositions stabilised over time, with unstable early communities while late communities 
309 were more stable due to community convergence. The transition from unstable to stable

310 compositions is seen in both developing and disrupted communities as they undergo rapid

311 changes as ecological niches develop and fill in response to rapid condition changes. These

312 rapid changes therefore cause disturbed communities to 'reset' ${ }^{47}$. As such, our observations

313 regarding early communities (day 7-14 within prokaryotes and day 7 within eukaryotes) are

314 applicable to both new and recently disturbed communities.

315 Substrate differences drive early composition

316 Increased degradability and subsequent higher nutrient availability and roughness of wood

317 could be responsible for higher richness in early predated conditions. Grooves within rough

318 surfaces increase the degree of colonisation through increased surface area, and protection

319 from shear stress and large predators ${ }^{48}$. Increased richness is therefore expected of rougher

320 surfaces such as wood ${ }^{49,50}$. However, wood also displayed a significantly dissimilar

321 community compared to other substrates under both exclusive and native conditions. The

322 organic carbon within wood in the form of lignocellulose is accessible to mixotrophic and

323 heterotrophic lignocellulose degraders (i.e. Proteobacteria and Bacteroidetes ${ }^{51,52}$ ), thereby

324 the organic carbon could act as an environmental filter. Inert substrates (i.e. plastic, glass, and

325 tile) cannot be degraded in the same manner, as such their early community was instead

326 primarily composed of autotrophs which fix their own carbon. Wood's organic carbon

327 availability therefore shapes early composition through the promotion of heterotrophic

328 growth.

329 We hypothesise that substrate dependent differences decrease over time due to increased 330 community density. Previous studies have shown that increased density leads to biofilm

331 heterogeneity ${ }^{53}$ as organisms further removed from the nutritional supply are affected by

332 solute diffusion limits ${ }^{53}$. In the context of our study, organisms further away from the 
333 substrate surface cannot utilise wood's nutritional organic carbon. Increased substrate

334 coverage and subsequent displacement from the substrate surface decreased differences

335 between degradable and inert substrates over time. We conclude that substrate dependent

336 differences decrease over time due to increased density limiting surface derived nutritional

337 supplies and protection to cause convergence. As seen in the similar community richness and

338 composition in late biofilms regardless of substrate type.

340 Predation decreased richness, although differences between substrates remained. The effects

341 of predation on microbial richness are relatively unexplored. Predation has been shown to

342 increase or decrease community richness, ${ }^{54,55}$ dependent on the net number of directly or

343 indirectly repressed/enriched organisms ${ }^{56}$. Our study determined that predation decreases

344 diversity. While substrate diversity effects could be identified, they remained mainly

345 predation-specific differences between substrates, e.g. wood showed increased richness

346 within early predated prokaryotes and late enclosed eukaryotes.

347 Predation affected late established communities to a greater extent than their early 348 counterparts. Late communities exhibited qualities associated with established ecosystems

34957,58 , via decreased richness and dissimilarity variability, indicative of increased community

350 stability. Early communities lack the inherent complexity and resources to sustain large

351 abundances of predators and other heterotrophic organisms, unlike their late counterparts ${ }^{41}$.

352 Predation significantly decreased late richness, but early richness remained unaffected.

353 Heterotrophs such as Arthropoda and Ciliophora increased in abundance over time and drove

354 their prey below detectable limits. Arthropoda prey on all microbial life ${ }^{59,60}$, whereas

355 Bacteroidetes prefer particulate detritus such as dead autotrophic Ochrophyta, while also

356 being capable of surface degradation ${ }^{51,61}$. Heterotrophic organism increases mirrored 
357 autotroph decreases, specifically Cyanobacteria and Ochrophyta. Predated conditions display

358 the autotroph to heterotroph shift over time as higher trophic levels preferentially preyed

359 upon heterotrophs.

360 Heterotrophs have been predicted to be more nutritious and thus a more important energy

361 source compared to autotrophs. Autotrophs display weak homeostasis, with stoichiometric

362 ratios shaped by the environment to a larger degree than the strongly homeostatic

363 heterotrophs ${ }^{62}$. Additionally, the environment, and therefore autotrophs, contains a higher

364 carbon to phosphorous ratio compared to heterotrophs ${ }^{62,63}$. The predation of stable and closer

365 stoichiometric matches leads to easier heterotrophic stoichiometric ratio maintenance,

366 making heterotrophs a better nutrient source compared to autotrophs. The closer

367 stoichiometric matches could explain the closer relationships between heterotrophs and

368 higher trophic levels ${ }^{64}$, such as the inverse relationship between Ciliophora (a heterotroph)

369 and Arthropoda (a eukaryotic predator). Previous findings corroborate the relationship:

370 Ciliophora (Ciliates) abundance declines corresponding with increases in Arthropoda

371 (Copepods), with no alternate prey availability effects ${ }^{65}$. Overall, we found that these

372 taxonomic responses confirm that predation is an important driver of late composition.

373 Previous work was completed within controlled environments with limited numbers of

374 external inputs, as opposed to the more complex and dynamic habitat approach of our

375 study $^{37}$. However, both previous and this study's findings agree that higher-order biotic

376 interactions play a critical role in complex microbiomes ${ }^{37}$. Often leading to community

377 convergence and stabilisation.

378 Alternative interpretation to our results are possible due to physical impacts of enclosure.

379 Enclosed conditions decrease the flow rate dependent nutrient supply and shear stress, as well

380 as light availability. A decreased organic nutrient supply leads to higher autotroph 
381 abundances as other organisms lack essential nutrients to fuel their growth and reproduction.

382 Enclosed conditions should therefore display higher autotroph abundances, but this was not

383 the case. Our study instead showed that autotrophs (i.e. Cyanobacteria, Florideophycidae, and

384 Ochrophyta) were, as a general rule, decreased within enclosed conditions. This could be due

385 to light availability limitations when over time more organisms settle on the mesh enclosure

386 and decrease light penetration, as well as the mesh itself providing shade ${ }^{66,67}$. Based on this a

387 linear relationship between autotrophs and time under enclosed conditions would be

388 expected, as more light is blocked with increased mesh community density. Instead

389 Cyanobacteria and Ochrophyta relative abundances under enclosed conditions peak at day 14

390 and 19, suggesting that light availability due to growth on the mesh may not be a large

391 contributing factor compared to other compositional drivers, while the inherent shade effect

392 of mesh may still play a role. Strong mesh inherent shade effects would lead to large

393 enclosure status effects throughout the study, due to large autotroph decreases within

394 exclusive communities. However, early community differences were primarily dependent on

395 substrate surface properties. Late community differences may be due to the mesh shade

396 effects, but this is also unlikely as enclosure status independent predation dynamics increased

397 over time, such as the close inverse relationship between Ochrophyta and Ciliophora.

398 Therefore, we conclude that community compositions were predominantly due to substrate

399 and predation effects, rather than the consistent effects of an inherent mesh shade. We also

400 considered that the presence of an enclosure may lead to community differences through

401 sheer stress mitigation ${ }^{68,69}$, but thought it unlikely due to the following reasons. First, shear

402 stress acts through biofilm biomass removal ${ }^{70}$ and should thereby equally affect all

403 organisms rather than selectively removing one group, so relative abundances would remain

404 the same. Second, a lack of shear stress would increase settlement, but no significant richness

405 difference exists between early enclosure conditions. Third, high stress has been shown to 
406 decrease biofilm maturation rates ${ }^{68,69}$, but the majority of compositional differences between

407 enclosures in our study was not due to maturation rate variations. Therefore enclosure

408 differences are more likely due to predator effects rather than shear stress removing biomass

409 and decreasing maturation rates.

410 Conclusion

411 Within our study we identified a switch from bottom-up to top-down control linked to

412 community maturation. This switch in primary selective pressure highlights the community

413 selection of primary colonisers, to the emergence of stable and convergent mature

414 communities modified by predation (Figure 5). Predation selectively removes organisms,

415 potentially using nutritional value as a criteria. The integration of top-down controls allowed

416 for the explanation of more variance than a pure solely bottom-up focus. Hence, increased

417 importance should be placed on top-down controls, particularly for studies on stable late

418 communities. The integration of both bottom-up and top-down selective pressures in the field

419 of microbial ecology leads to increased knowledge of assembly mechanism. This knowledge

420 would be applicable across all ecosystems, as the underlying framework rather than habitat

421 specific processes, is assessed. Ultimately identifying not only habitat specific community

422 compositions, but what lead to these compositional patterns. 


\section{Acknowledgements}

424 We thank Dave Wilson for his contribution to experimental set up.

425

426 Conflict of interests

427 The authors declare that they have no conflict of interest.

428

429 Data availability

430 The sequence data from this study have been deposited in NCBI under BioProject

431 PRJNA630803. All data generated and/or analysed during the study is available within the

432 GitHub repository, https://github.com/SvenTobias-Hunefeldt/Biofilm_2020/. 


\section{References}

436 1. Wade, W. Unculturable bacteria - The uncharacterized organisms that cause oral

437 infections. in Journal of the Royal Society of Medicine vol. 95 81-83 (2002).

$438 \quad 2 . \quad$ Stewart, E. J. Growing unculturable bacteria. Journal of Bacteriology vol. $1944151-$

$4394160(2012)$.

440 3. Estes, J. A. \& Palmisano, J. F. Sea otters: Their role in structuring nearshore communities. Science (80-. ). 185, 1058-1060 (1974).

4. Rajput, R., Pokhriya, P., Panwar, P., Arunachalam, A. \& Arunachalam, K. Soil nutrients, microbial biomass, and crop response to organic amendments in rice cropping system in the Shiwaliks of Indian Himalayas. Int. J. Recycl. Org. Waste Agric. 8, 73-85 (2019).

5. Ofiţeru, I. D. et al. Combined niche and neutral effects in a microbial wastewater treatment community. Proc. Natl. Acad. Sci. U.S. A. 107, 15345-15350 (2010).

448 6. Pereira e Silva, M. C., Dias, A. C. F., van Elsas, J. D. \& Salles, J. F. Spatial and Temporal Variation of Archaeal, Bacterial and Fungal Communities in Agricultural Soils. PLoS One 7, e51554 (2012).

451 7. Nemergut, D. R. et al. Patterns and Processes of Microbial Community Assembly. Microbiol. Mol. Biol. Rev. 77, 342-356 (2013).

453 8. Evans, S., Martiny, J. B. H. \& Allison, S. D. Effects of dispersal and selection on stochastic assembly in microbial communities. ISME J. 11, 176-185 (2017). Ecology? Microbiol. Mol. Biol. Rev. 81, (2017). mechanisms that mediate the balance between stochastic and deterministic processes in microbial succession. Proc. Natl. Acad. Sci. U. S. A. 112, E1326-E1332 (2015). 
460 11. Ju, F., Xia, Y., Guo, F., Wang, Z. \& Zhang, T. Taxonomic relatedness shapes bacterial

461 assembly in activated sludge of globally distributed wastewater treatment plants. Environ. Microbiol. 16, 2421-2432 (2014).

12. Wang, J. et al. Phylogenetic beta diversity in bacterial assemblages across ecosystems: Deterministic versus stochastic processes. ISME J. 7, 1310-1321 (2013).

13. Chase, J. M. \& Myers, J. A. Disentangling the importance of ecological niches from stochastic processes across scales. Philos. Trans. R. Soc. B Biol. Sci. 366, 2351-2363 (2011).

14. Awet, T. T. et al. Effects of polystyrene nanoparticles on the microbiota and functional diversity of enzymes in soil. Environ. Sci. Eur. 30, 11 (2018).

15. Price, P. B. \& Sowers, T. Temperature dependence of metabolic rates for microbial growth, maintenance, and survival. Proc. Natl. Acad.Sci. U.S. A. 101, 4631-4636 (2004).

16. Bartlett, D. H. Pressure effects on in vivo microbial processes. Biochimica et Biophysica Acta - Protein Structure and Molecular Enzymology vol. 1595 367-381 (2002).

17. Damore, J. A. \& Gore, J. Understanding microbial cooperation. J. Theor. Biol. 299, $31-41(2012)$.

18. Knowlton, N. \& Rohwer, F. Multispecies Microbial Mutualisms on Coral Reefs: The Host as a Habitat. in American Naturalist vol. 162 (2003).

19. Shoemaker, K. M., Duhamel, S. \& Moisander, P. H. Copepods promote bacterial community changes in surrounding seawater through farming and nutrient enrichment. Environ. Microbiol. (2019) doi:10.1111/1462-2920.14723. composition of planktonic bacteria. Antonie van Leeuwenhoek, Int. J. Gen. Mol. 
485

486

487

488

489

490

491

492

493

494

495

496

497

498

499

500

501

502

503

504

505

506

507

508

509

Microbiol. 81, 413-434 (2002).

21. Sherr, E. B. \& Sherr, B. F. Significance of predation by protists in aquatic microbial food webs. Antonie van Leeuwenhoek, Int. J. Gen. Mol. Microbiol. 81, 293-308 (2002).

22. Gilbert, J. A. et al. Defining seasonal marine microbial community dynamics. ISME J. 6, 298-308 (2012).

23. Pacheco, A. R. \& Segrè, D. A multidimensional perspective on microbial interactions. FEMS Microbiol. Lett. 366, (2019).

24. Coleman, M. L. \& Chisholm, S. W. Ecosystem-specific selection pressures revealed through comparative population genomics. Proc. Natl. Acad.Sci. U. S. A. 107, 18634$18639(2010)$.

25. Freestone, A. L. et al. Predation shapes invertebrate diversity in tropical but not temperate seagrass communities. J. Anim. Ecol. 89, 323-333 (2020).

26. Hutchinson, G. E. Homage to Santa Rosalia or Why Are There So Many Kinds of Animals? Am. Nat. 93, 145-159 (1959).

27. Holt, A. R., Davies, Z. G., Tyler, C. \& Staddon, S. Meta-Analysis of the Effects of Predation on Animal Prey Abundance: Evidence from UK Vertebrates. PLoS One 3, e2400 (2008)

28. del Giorgio, P. A. \& Bouvier, T. C. Linking the physiologic and phylogenetic successions in free-living bacterial communities along an estuarine salinity gradient. Limnol. Oceanogr. 47, 471-486 (2002).

29. Lee, C. K. et al. Biotic interactions are an unexpected yet critical control on the complexity of an abiotically driven polar ecosystem. Commun. Biol. 2, (2019).

30. Gasol, J. M. A framework for the assessment of top-down vs bottom up control of heterotrophic nanoflagellate abundance. Mar. Ecol. Prog. Ser. 113, 291-300 (1994). 
510 31. Rosińska, J., Romanowicz-Brzozowska, W., Kozak, A. \& Gołdyn, R. Zooplankton

511 changes during bottom-up and top-down control due to sustainable restoration in a

512 shallow urban lake. Environ. Sci. Pollut. Res. 1-13 (2019) doi:10.1007/s11356-019-

$513 \quad 05107-z$

514 32. Berdjeb, L., Ghiglione, J. F. \& Jacquet, S. Bottom-up versus top-down control of

515 hypo-and epilimnion free-living bacterial community structures in two neighboring

516 freshwater lakes. Appl. Environ. Microbiol. 77, 3591-3599 (2011).

517 33. Sakharova, E. G. et al. Dynamics of Species and Size Structures of Phytoplankton at

518 Different Levels of Bottom-Up and Top-Down Effects in Experimental Conditions.

519 Contemp. Probl. Ecol. 12, 245-253 (2019).

520 34. Grattepanche, J.-D., Juarez, D. L., Wood, C. C., McManus, G. B. \& Katz, L. A. Topdown and bottom-up effects on microbial eukaryotic diversity inferred from molecular

35. Lami, R., Ghiglione, J. F., Desdevises, Y., West, N. J. \& Lebaron, P. Annual patterns of presence and activity of marine bacteria monitored by 16S rDNA-16S rRNA fingerprints in the coastal NW Mediterranean Sea. Aquat. Microb. Ecol. 54, 199-210 (2009).

36. Scepanovic, P. et al. A comprehensive assessment of demographic, environmental, and host genetic associations with gut microbiome diversity in healthy individuals.

530 37. Goldford, J. E. et al. Emergent simplicity in microbial community assembly. Science (80-. ). 361, 469-474 (2018).

532 38. Ripple, W. J. et al. Status and ecological effects of the world's largest carnivores. Science vol. 343 (2014).

534 39. Ferrenberg, S. et al. Changes in assembly processes in soil bacterial communities 
following a wildfire disturbance. ISME J. 7, 1102-1111 (2013).

40. Cohen, J. E., Pimm, S. L., Yodzis, P. \& Saldana, J. Body Sizes of Animal Predators and Animal Prey in Food Webs. J. Anim. Ecol. 62, 67 (1993).

41. Antunes, J., Leão, P. \& Vasconcelos, V. Marine biofilms: diversity of communities and of chemical cues. Environ. Microbiol. Rep. 11, 287-305 (2019).

42. Langenheder, S., Lindström, E. S. \& Tranvik, L. J. Structure and function of bacterial communities emerging from different sources under identical conditions. Appl. Environ. Microbiol. 72, 212-220 (2006).

43. Caruso, T. et al. Stochastic and deterministic processes interact in the assembly of desert microbial communities on a global scale. ISME J. 5, 1406-1413 (2011).

44. Johansen, R. et al. Tracking Replicate Divergence in Microbial Community (2019).

45. Castle, S. C. et al. Biogeochemical drivers of microbial community convergence across actively retreating glaciers. Soil Biol. Biochem. 101, 74-84 (2016).

46. Pagaling, E. et al. Community history affects the predictability of microbial ecosystem development. ISME J. 8, 19-30 (2014).

48. Characklis, W. G., McFeters, G. A. \& Marshall, K. C. Physiological ecology in 
560 50. Eginton, P. J., Gibson, H., Holah, J., Handley, P. S. \& Gilbert, P. The influence of substratum properties on the attachment of bacterial cells. Colloids Surfaces B Biointerfaces 5, 153-159 (1995).

51. Smith, M. W., Herfort, L., Fortunato, C. S., Crump, B. C. \& Simon, H. M. Microbial players and processes involved in phytoplankton bloom utilization in the water column of a fast-flowing, river-dominated estuary. Microbiologyopen 6, (2017).

52. Bredon, M., Dittmer, J., Noël, C., Moumen, B. \& Bouchon, D. Lignocellulose degradation at the holobiont level: Teamwork in a keystone soil invertebrate 06 Biological Sciences 0605 Microbiology. Microbiome 6, 1-19 (2018).

53. Stewart, P. S. \& Franklin, M. J. Physiological heterogeneity in biofilms. Nature Reviews Microbiology vol. 6 199-210 (2008).

54. Antiqueira, P. A. P., Petchey, O. L. \& Romero, G. Q. Warming and top predator loss drive ecosystem multifunctionality. Ecology Letters vol. 21 72-82 (2018).

55. Holt, R. D. \& Lawton, J. H. The ecological consequences of shared natural enemies. Annual Review of Ecology and Systematics vol. 25 495-520 (1994).

56. Schoener, T. W. \& Spiller, D. A. Devastation of prey diversity by experimentally introduced predators in the field. 381, 691-694 (1996).

57. Bik, H. M. et al. Microbial Community Succession and Nutrient Cycling Responses following Perturbations of Experimental Saltwater Aquaria. mSphere 4, (2019).

58. Tanaka, M. \& Nakayama, J. Development of the gut microbiota in infancy and its impact on health in later life. Allergology International vol. $66515-522$ (2017).

59. Han, P. et al. Global change-driven modulation of bottom-up forces and cascading effects on biocontrol services. Curr. Opin. Insect Sci. (2019) doi:10.1016/j.cois.2019.05.005.

584 60. Thorp, J. H. \& Rogers, D. C. Introduction to the Phylum Arthropoda. in Thorp and 
Covich's Freshwater Invertebrates: Ecology and General Biology: Fourth Edition vol. 1 591-597 (Elsevier Inc., 2014).

61. Thomas, F., Hehemann, J. H., Rebuffet, E., Czjzek, M. \& Michel, G. Environmental and gut Bacteroidetes: The food connection. Front. Microbiol. 2, (2011).

62. Hessen, D. O., Elser, J. J., Sterner, R. W. \& Urabe, J. Ecological stoichiometry: An elementary approach using basic principles. Limnol. Oceanogr. 58, 2219-2236 (2013).

63. Iv, F. B., Menge, D. N. L., Ostling, A. \& Hosseini, P. Nutrient Recycling Affects Autotroph and Ecosystem Stoichiometry. 171, (2008).

64. Yang, J. W. et al. Predator and prey biodiversity relationship and its consequences on marine ecosystem functioning - Interplay between nanoflagellates and bacterioplankton. ISME J. 12, 1532-1542 (2018).

65. Broglio, E., Saiz, E., Calbet, A., Trepat, I. \& Alcaraz, M. Trophic impact and prey selection by crustacean zooplankton on the microbial communities of an oligotrophic

66. Dawson, F. H. \& Kern-Hansen, U. The Effect of Natural and Artificial Shade on the Macrophytes of Lowland Streams and the Use of Shade as a Management Technique. Int. Rev. der gesamten Hydrobiol. und Hydrogr. 64, 437-455 (1979). STRESS DRIVE A MARINE PLANT-HERBIVORE ASSOCIATION. Ecology 85, 2837-2849 (2004).

68. Catão, E. C. P. et al. Shear Stress as a Major Driver of Marine Biofilm Communities in the NW Mediterranean Sea. Front. Microbiol. 10, 1768 (2019). 4915-4922 (2008). 
$61070 . \quad$ Rittman, B. E. The effect of shear stress on biofilm loss rate. Biotechnology and $611 \quad$ Bioengineering vol. 24 501-506(1982).

612 71. R Core Team. R: A Language and Environment for Statistical Computing. (2019).

613 72. Wickham, H. ggplot2: Elegant Graphics for Data Analysis. (Springer-Verlag New $614 \quad$ York, 2016).

615 73. Caporaso, J. G. et al. Ultra-high-throughput microbial community analysis on the 616 Illumina HiSeq and MiSeq platforms. ISME J. 6, 1621-1624 (2012).

617 74. Callahan, B. J. et al. DADA2: High-resolution sample inference from Illumina $618 \quad$ amplicon data. Nat. Methods 13, 581-583 (2016).

619 75. Wang, Q., Garrity, G. M., Tiedje, J. M. \& Cole, J. R. Naïve Bayesian classifier for rapid assignment of rRNA sequences into the new bacterial taxonomy. Appl. Environ.

622 76. McMurdie, P. J. \& Holmes, S. Phyloseq: An R Package for Reproducible Interactive Analysis and Graphics of Microbiome Census Data. PLoS One 8, (2013).

624 77. Wickham, H. Reshaping data with the reshape package. J. Stat. Softw. 21, 1-20 (2007).

78. Wickham, H. The Split-Apply-Combine Strategy for Data Analysis. J. Stat. Softw. 40, $1-29(2011)$.

79. Dowle, M. \& Srinivasan, A. data.table: Extension of 'data.frame'. R Packag. version $1.12 .6(2019)$.

80. Kassambara, A. ggpubr: 'ggplot2' Based Publication Ready Plots. (2019).

631 81. Oksanen, J. et al. vegan: Community Ecology Package. (2019) doi:intro-vegan.Rnw (2010-12-16) on January 10, 2011.

634 82. Wickham, H., François, R., Henry, L. \& Müller, K. dplyr: A Grammar of Data 
635 Manipulation. (2019).

636 83. Latombe, G., McGeoch, M. A., Nipperess, D. A. \& Hui, C. zetadiv: Functions to

637 Compute Compositional Turnover Using Zeta Diversity. R package version 1.1.1

$638 \quad(2018)$

639 84. Robinson, M. D., McCarthy, D. J. \& Smyth, G. K. edgeR: A Bioconductor package for 640 differential expression analysis of digital gene expression data. Bioinformatics 26, $641 \quad 139-140(2010)$.

642 85. Wickham, H. forcats: Tools for Working with Categorical Variables (Factors). (2019).

643 86. Waite, D. W. et al. Comparative genomic analysis of the class Epsilonproteobacteria 644 and proposed reclassification to epsilonbacteraeota (phyl. nov.). Front. Microbiol. 8, $645 \quad$ (2017).

646 87. Bhatnagar, M. \& Bhatnagar, A. Diversity of Polysaccharides in Cyanobacteria. in Microbial Diversity in Ecosystem Sustainability and Biotechnological Applications 447-496 (Springer Singapore, 2019). doi:10.1007/978-981-13-8315-1_15.

88. Sukenik, A., Zohary, T. \& Padisák, J. Cyanoprokaryota and Other Prokaryotic Algae. in Encyclopedia of Inland Waters 138-148 (Elsevier Inc., 2009). doi:10.1016/B978012370626-3.00133-2.

89. Cavalier-Smith, T. Kingdom Chromista and its eight phyla: a new synthesis emphasising periplastid protein targeting, cytoskeletal and periplastid evolution, and ancient divergences. Protoplasma 255, 297-357 (2018).

90. Carere, C. R. et al. Mixotrophy drives niche expansion of verrucomicrobial methanotrophs. ISME J. 11, 2599-2610 (2017). 
660 92. Wexler, H. M. Bacteroides: The good, the bad, and the nitty-gritty. Clinical Microbiology Reviews vol. 20 593-621 (2007).

662 93. Spring, S. et al. Characterization of the first cultured representative of

663

664 Verrucomicrobia subdivision 5 indicates the proposal of a novel phylum. ISME J. 10,

94. Fujio-Vejar, S. et al. The gut microbiota of healthy Chilean subjects reveals a high abundance of the phylum Verrucomicrobia. Front. Microbiol. 8, (2017).

95. Majdi, N. \& Traunspurger, W. Free-living nematodes in the freshwater food web: A review. Journal of Nematology vol. 47 28-44 (2015).

96. Dong, Y. et al. Roles of three TonB systems in the iron utilization and virulence of the Aeromonas hydrophila Chinese epidemic strain NJ-35. Appl. Microbiol. Biotechnol.

97. Lee, K. C. et al. Phylum Verrucomicrobia representatives share a compartmentalized cell plan with members of bacterial phylum Planctomycetes. BMC Microbiol.9, (2009).

98. Yeates, G. W., Bongers, T., De Goede, R. G. M., Freckman, D. W. \& Georgieva, S. S. Feeding Habits in Soil Nematode Families and Genera-An Outline for Soil Ecologists.

99. Suyama, T. et al. Photosynthetic apparatus in Roseateles depolymerans $61 \mathrm{~A}$ is transcriptionally induced by carbon limitation. Appl. Environ. Microbiol. 68, 16651673 (2002). 
684 Figure Legends

685 Figure 1. Marine biofilm development occurs in two stages. Community richness changes

686 over time are seen for both prokaryotic (A) and eukaryotic (B) organisms. Also shown is the 687 intra-time point community dissimilarity of each biofilm (C) and the shared number of ASVs 688 (Amplicons Sequence Variants) between substrates over time (D). Colours depict both different substrates (A \& B), organisms (C), and enclosure conditions (D). Black, green, blue, and magenta represent plastic, glass, tile, and wood (A \& B), while red and blue represent

691 prokaryotic and eukaryotic organisms (C), and black and orange represent exclusive 692 (enclosed) and native (non-enclosed) conditions (D). Error bars represent standard deviation.

Figure 2. Microbial biofilm beta-diversity by time. NMDS plots show prokaryotes (A) and eukaryotes (B), ellipses depict the 95\% confidence interval grouping effects of time with biofilm age represented as different colours (days 7, 14, 19, 28, 42, and 56 depicted as olive, black, red, navy, green, and magenta). Substrates are depicted with different shapes, the hollow diamond represents wood whereas the filled square, circle, and triangle represent plastic, glass, and tile. Stress is included in the upper left corner of individual plots.

Figure 3. Prokaryotic and eukaryotic observed richness is enclosure specific in a stage

dependent manner. Marine in situ biofilm species richness for both prokaryotes (A) and

703 eukaryotes (B) is shown by developmental stage grouping. The black horizontal line

704 represents the organisms and stage specific richness mean, while colours separate the

705 different substrates. Plastic, glass, tile, and wood is depicted in black, red, navy, and green.

706 Wilcoxon tests assessed the significance of stage specific enclosure differences, and Kruskal-

707 Wallis tests identified the significance of substrate effects in a stage and enclosure specific manner. 
710 Figure 4. Significant phylum changes in response to biofilm age. The mean relative

711 abundance of significantly prokaryotic (A) and eukaryotic (B) phyla correlated with biofilm

712 age are depicted with exclusive (enclosed) communities on the left and native (non-enclosed)

713 on the right in a substrate dependent manner. The type of line (solid, points, and dashed)

714 represent the three main types of organisms; autotrophs, heterotrophs, and mixotrophs. Mean

715 relative abundance was calculated from pooled significantly correlated taxa and error bars

716 represent the standard error of the mean abundance based on biological replicates.

Figure 5. Microbial biofilm community assembly is divided into discrete stages

from the environmental organism pool known as the metacommunity and filtered in response

to a selective pressure. Selective pressures filter for distinct community compositions. First, bottom-up (early stage) substrate differences and then top-down (late stage) enclosure status determine biofilm community composition, with decreased bottom-up differences due to topdown filtering.

Table 1. ANOSIM and ADONIS tests compare time, substrate and enclosure correlations over time on biofilm prokaryotes and eukaryotes.

Supplementary Figure 1. Biofilm holder construction and deployment. Individual $75 \mathrm{x}$

$73025 \mathrm{~mm}$ substrate (i.e. plastic, glass, tile, and wood) slides were contained within $50 \mathrm{~mm}$ PVC

731 pipe sections with a diameter of $100 \mathrm{~mm}$ with the use of polyethylene foam and ethyl 732 cyanoacrylate. Predators were excluded with the use of a $100 \mu \mathrm{m}$ mesh surrounding the 733 substrate filled PVC pipe section, whereas native (non-enclosed) samples lacked a mesh 
734 enclosure. Samples were suspended from either their mesh enclosure or pipe on a single $30 \mathrm{~m}$

735 rope on the surface during low tide $80 \mathrm{~cm}$ from the seabed, so high tide submerged samples.

736

737 Supplementary Figure 2. Prokaryotic and eukaryotic organism rarefaction curves.

738 Mean observed richness was identified in response to sampling depth for prokaryotes (A) and

739 eukaryotes (B), with 10 replicate rarefaction and richness determination events. Different

740 colours represent biofilm age, and error bars represent the standard deviation of individual

741 sample replicates.

742

743

Supplementary Figure 3. Development stage evidence based on a silhouette and ecotone

analysis for prokaryotes (left) and eukaryotes (right). Determination of the ecotone transition zone $(\mathrm{A}, \mathrm{B})$ and a silhouette analysis $(\mathrm{C}, \mathrm{D})$ was carried out for both prokaryotic $(\mathrm{A}, \mathrm{C})$ and eukaryotic $(\mathrm{B}, \mathrm{D})$ organisms. The ecotone analysis was done using biofilm age as a distance proxy to facilitate analysis. Colours represent the two identified groups with the average species abundance and biofilm age depicted on the $\mathrm{y}$ axis and $\mathrm{x}$ axis. prokaryotic (A) and eukaryotic (B) organism beta-diversity, colours separate the early (black) and late (red) succession stages, surrounded by 95\% confidence interval ellipses. The enclosure status is depicted with different shapes, the hollow diamond represents native (nonenclosed) samples whereas the filled circle represents exclusive (enclosed) samples. study, based on time of sampling, and community source. 
759 Supplementary Table 2. Significant taxonomic changes over time. Significant relative

760 taxonomic (i.e. family) changes in response to biofilm age separated by substrate and

761 enclosure status. 
A

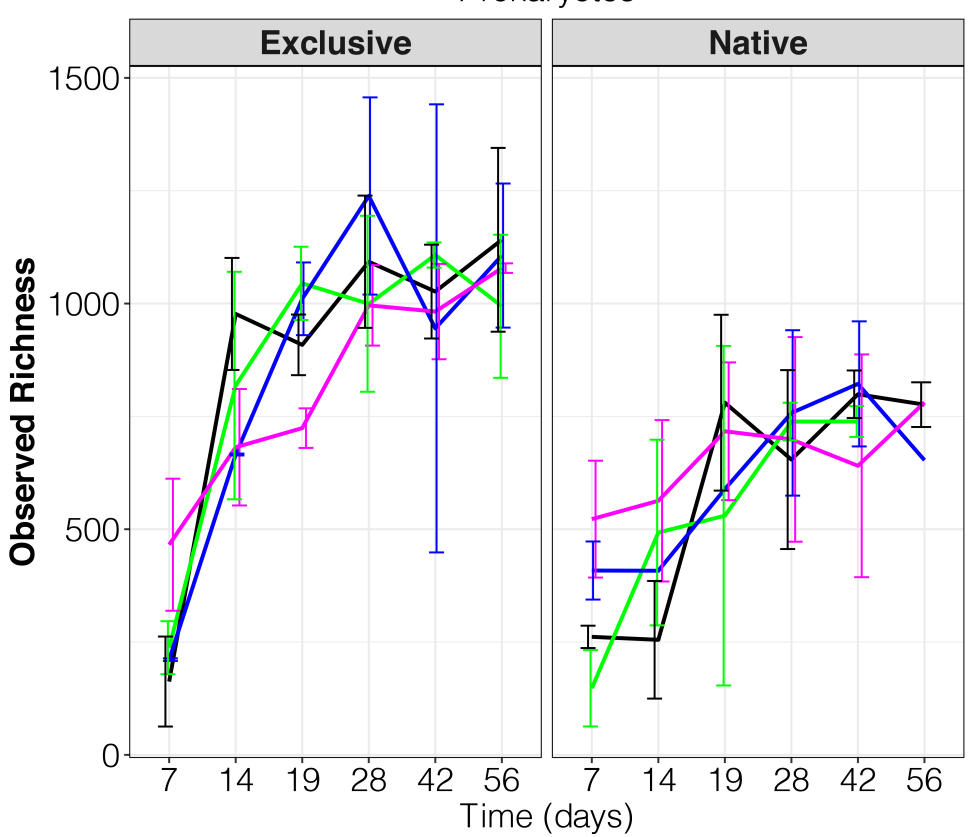

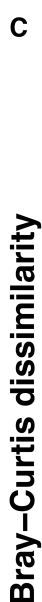

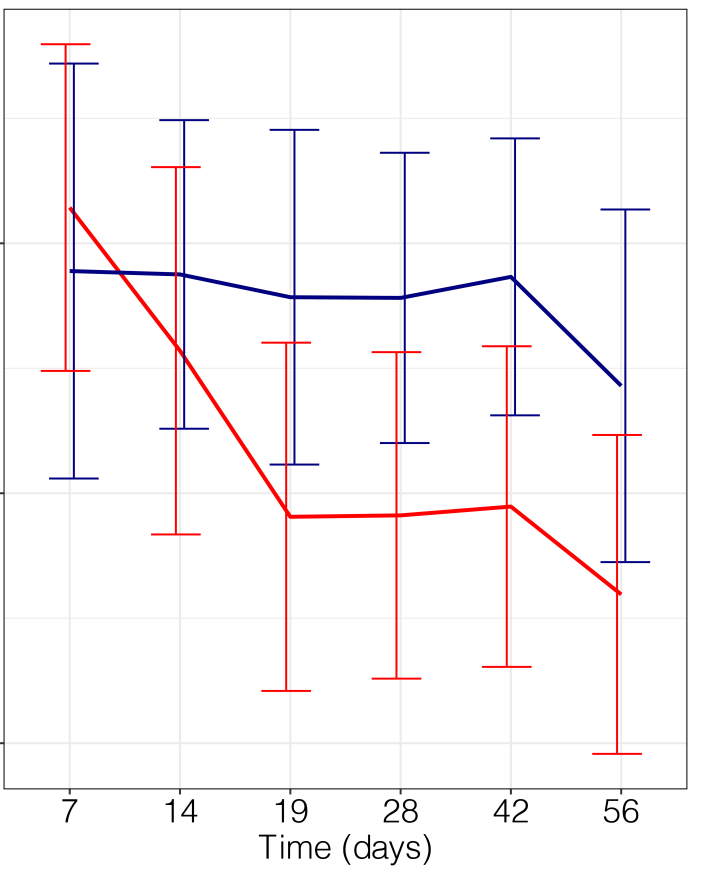

B

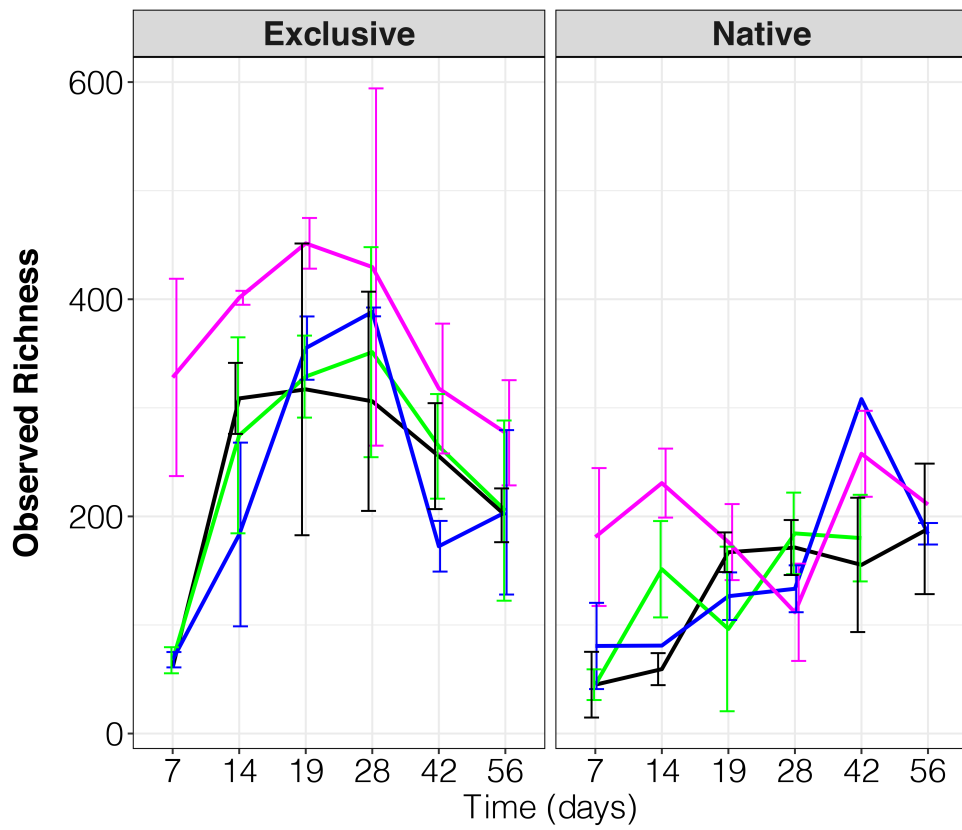

Condition

- Plastic

- Glass

- Tile

- Wood
D

Organism

- Prokaryotes

- Eukaryotes

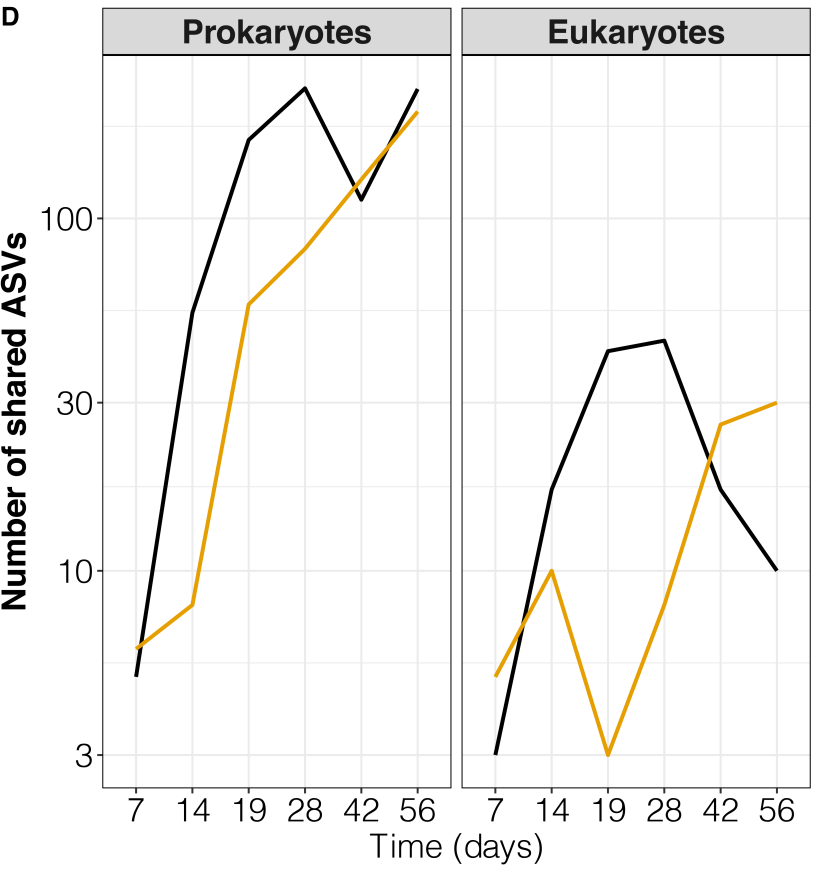

Condition

- Exclusive

- Native 
bioRxiv preprint doi: https://doi.org/10.1101/2020.08.06.233379; this version posted Auqust 6, 2020. The copyright holder for this preprint (which was not certified by peer review) is the author/funder, who has granted bioRxiv a license to display the preprint in perpetuity. It is made available under aCC-BY-ND 4.0 International license.

A
乏
ญू
Z

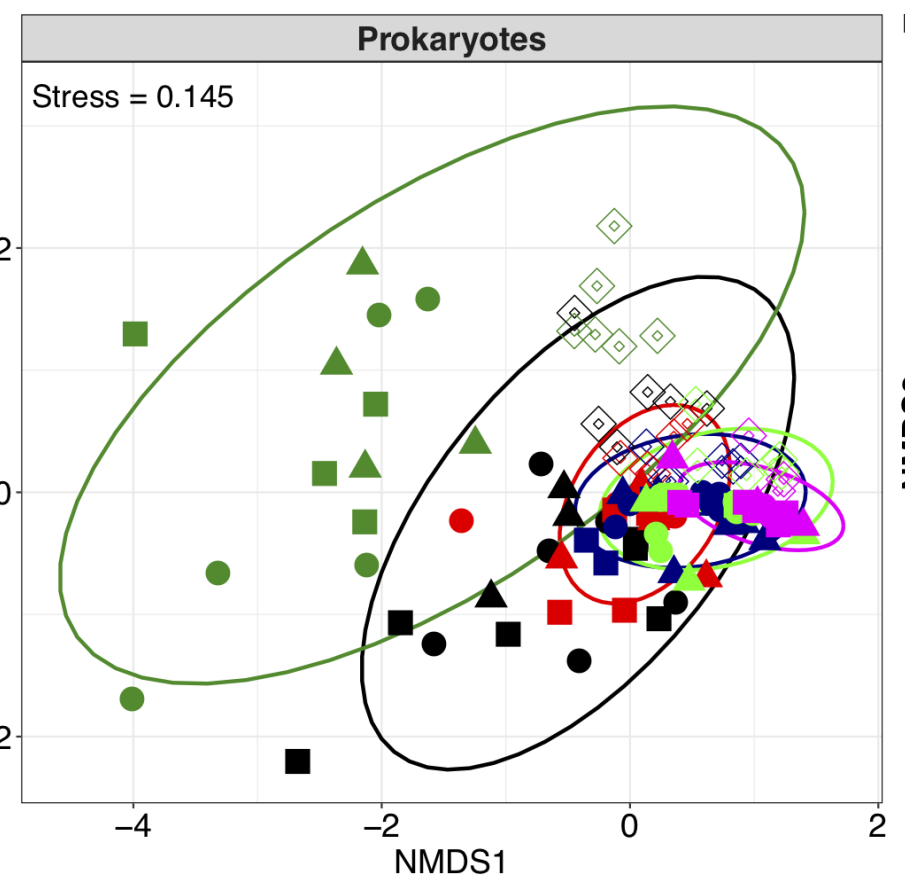

B

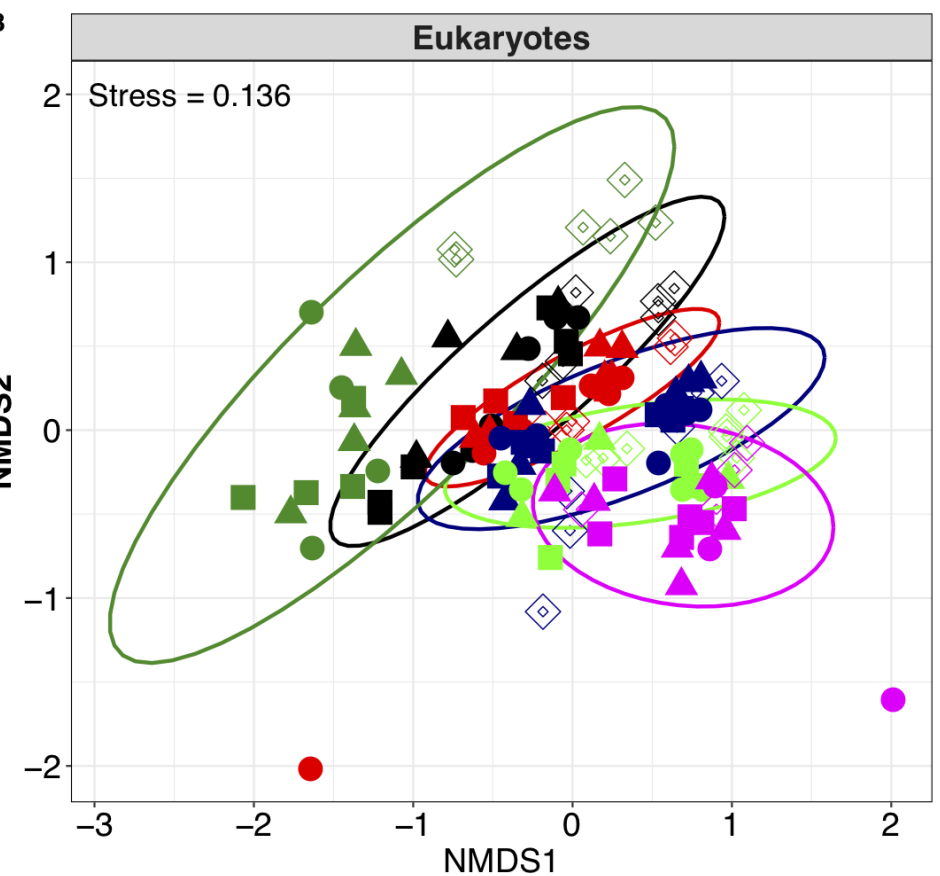

Time (days)

$\rightarrow 7$

$\rightarrow 14$

$\rightarrow 19$

- 28

$-42$

- 56

Substrate

- Plastic

- Glass

- Tile

$\diamond$ Wood 
bioRxiv preprint doi: https://doi.org/10.1101/2020.08.06.233379; this version posted August 6, 2020. The copyright holder for this preprint (which was not certified by peer review) is the author/funder, who has granted bioRxiv a license to display the preprint in perpetuity. It is made available under aCC-BY-ND 4.0 International license.
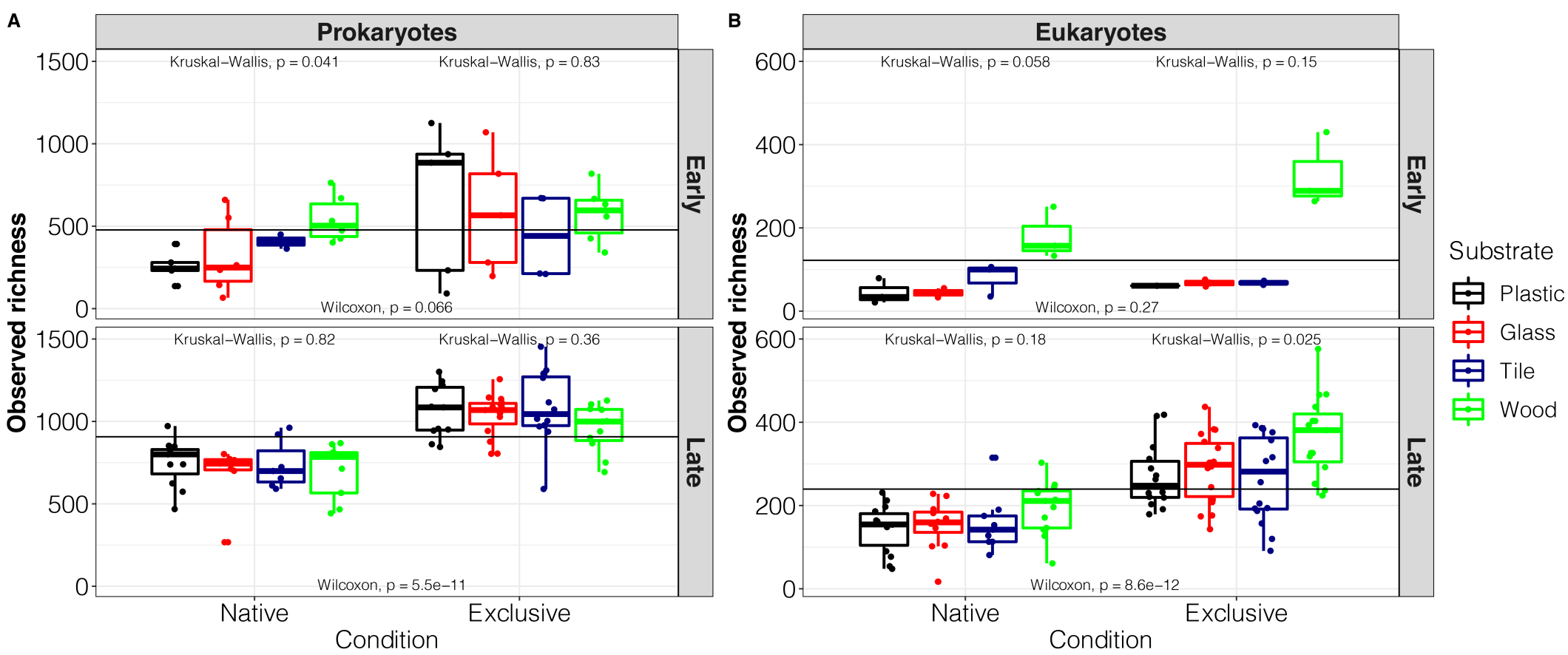


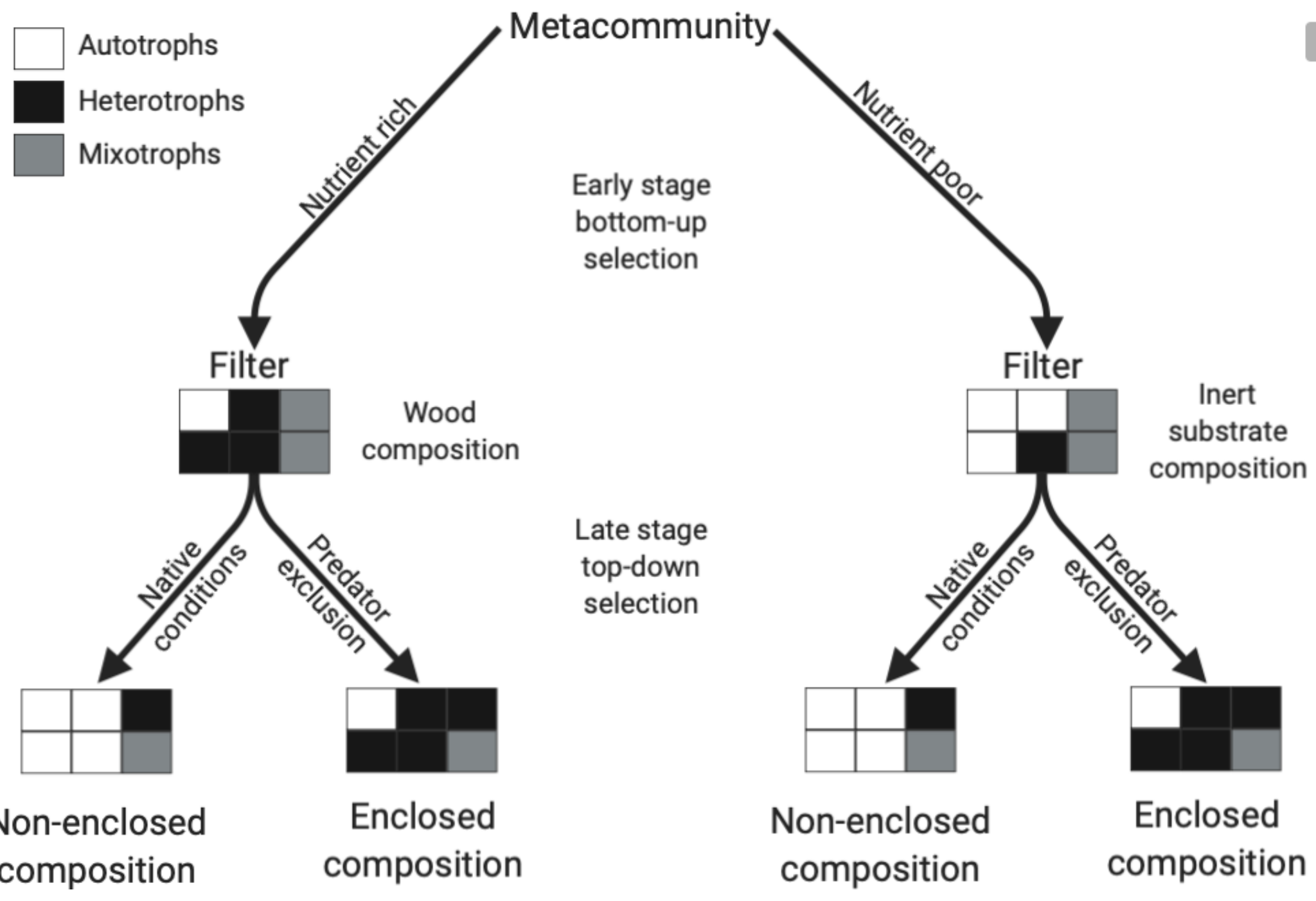


bioRxiv preprint doi: https://doi.org/10.1101/2020.08.06.233379; this version posted August 6, 2020. The copyright holder for this preprint (which was not certified by peer review) is the author/funder, who has granted bioRxiv a license to display the preprint in perpetuity. It is made available under aCC-BY-ND 4.0 International license.

Table 1. ANOSIM and ADONIS tests compare time, substrate and enclosure correlations over time on biofilm prokaryotes and eukaryotes.

\begin{tabular}{|c|c|c|c|c|c|}
\hline Organism & Test & Biofilm development stage & Variable & $R / R^{2}$ & $p$ value \\
\hline \multirow{12}{*}{ Prokaryotes } & \multirow{6}{*}{ Anosim } & \multirow{3}{*}{ Early } & Time & 0.3 & $<0.01$ \\
\hline & & & Substrate & 0.5 & $<0.01$ \\
\hline & & & Enclosure status & 0.19 & $<0.01$ \\
\hline & & \multirow{3}{*}{ Late } & Time & 0.3 & $<0.01$ \\
\hline & & & Substrate & 0.19 & $<0.01$ \\
\hline & & & Enclosure status & 0.41 & $<0.01$ \\
\hline & \multirow{6}{*}{ Adonis } & \multirow{3}{*}{ Early } & Time & 0.11 & $<0.01$ \\
\hline & & & Substrate & 0.24 & $<0.01$ \\
\hline & & & Enclosure status & 0.08 & $<0.01$ \\
\hline & & \multirow{3}{*}{ Late } & Time & 0.13 & $<0.01$ \\
\hline & & & Substrate & 0.12 & $<0.01$ \\
\hline & & & Enclosure status & 0.13 & $<0.01$ \\
\hline \multirow{12}{*}{ Eukaryotes } & \multirow{6}{*}{ Anosim } & \multirow{3}{*}{ Early } & Time & NA & \\
\hline & & & Substrate & 0.34 & $<0.01$ \\
\hline & & & Enclosure status & 0.52 & $<0.01$ \\
\hline & & \multirow{3}{*}{ Late } & Time & 0.32 & $<0.01$ \\
\hline & & & Substrate & 0.06 & $<0.01$ \\
\hline & & & Enclosure status & 0.23 & $<0.01$ \\
\hline & \multirow{6}{*}{ Adonis } & \multirow{3}{*}{ Early } & Time & NA & \\
\hline & & & Substrate & 0.28 & 0.014 \\
\hline & & & Enclosure status & 0.18 & $<0.01$ \\
\hline & & \multirow{3}{*}{ Late } & Time & 0.16 & $<0.01$ \\
\hline & & & Substrate & 0.05 & 0.018 \\
\hline & & & Enclosure status & 0.07 & $<0.01$ \\
\hline
\end{tabular}

